https://doi.org/10.48009/2_iis_2007_425-429

\title{
IMPLEMENTING ENTERPRISE RESOURCE PLANNING (ERP) FOR STRATEGIC COMPETITIVE ADVANTAGE
}

\author{
Karen A. Forcht, North Carolina A \& T State University, kaforcht@ncat.edu \\ Eric Kieschnick, Texas A \& M University-Kingsville, eak2278@hotmail.com \\ Alicia Aldridge, Appalachian State University, alicia@appstate.edu \\ Jack D. Shorter, Texas A \& M University-Kingsville, jackshorter@hotmail.com
}

\begin{abstract}
This paper discusses the definition of an ERP system using packaged software that enables a company to make efficient use of corporate resources. These resources include materials, human resources, finance, sales, marketing, finance, etc. ERP provides a total, integrated solution for all of the organization's information processing needs. This paper also discusses why ERP projects often fail and how organizations can insure success of the ERP implementation. Critical Success Factors (CSF) of ERP implementation are discussed, which include appropriate business and IT legacy systems, business plan and vision, business process reengineering $(B P R)$, change management culture and programs, effective communication, teamwork and composition of teams, monitoring and evaluation of performance, project champions, project management, software development, testing and troubleshooting, top management support, etc.
\end{abstract}

Keywords: ERP, CSF, change management, BPR, project champion, project management, software troubleshooting.

\section{INTRODUCTION}

An enterprise resource planning (ERP) system is a packaged software system that enables a company to manage the efficient and effective use of resources (inventory, materials, human resources, sales, marketing, finance, customer information, etc.) by providing a total, integrated solution for its information processing needs. [4] ERP allows an organization to gain competitive advantages by saving resources and responding to the constantly changing business environment. ERP can deliver powerful results by coordinating information that ultimately increases customer satisfaction and brand equity. [4] Many organizations, both large and small, have or will implement ERP systems in an attempt to gain a strategic position by coordinating business processes and removing departmental separation that inhibits effective and efficient communication. [5]
ERP software runs the core operations of a business, including marketing, transportation, finance/accounting, production, inventory, order management, procurement, customer relationship management, and human resources management. However, implementations have often been fragmented and departmentalized, and different applications have had varying levels of success.

\section{Definition of ERP}

Enterprise resource planning software, or ERP, does not live up to its acronym. Forget about planning-it doesn't do much of that-and forget about resource, a throwaway term. But remember the enterprise part. This is ERP's true ambition. The software attempts to integrate all departments and functions across a company into a single computer system that can serve all those departmental individual needs.

Building a single software program that serves the needs of people in finance, as well as it does the people in marketing and in the warehouse is a tall order. Each of those departments typically has its own computer system optimized for the particular ways that the department does its work. But ERP combines them all together into a single, integrated software program that runs off a single database so that the various departments can more easily share information and communicate with each other. That integrated approach can have a tremendous payback if companies install the software correctly.[4]

Take a customer order, for example. Typically, when a customer places an order, that order begins a mostly paper-based journey from inbox to inbox throughout the company, often being keyed and re-keyed into different department's computer systems along the way. All that "lounging around" in inboxes causes delays and lost orders, and all the keying into different computer systems invites errors. Meanwhile, no one individual in the company truly knows what the status of the order is at any given point because there is no way for salespeople, for example, to get into the warehouse's computer 
system to see whether the item has been shipped. "You'll have to call the warehouse" is the familiar refrain heard by frustrated customers.

ERP vanquishes the old standalone computer systems in marketing, finance, HR, manufacturing and the warehouse, and replaces them with a single unified software program divided into software modules that roughly approximate the old standalone systems. Logistics, finance, manufacturing and the warehouse all still get their own software, except now the software is linked together so that someone in the sales department or finance can look into the warehouse software to see if an order has been shipped. Back in the '90s ERP was developed as a tightly integrated monolith, but most vendors' software has since become flexible enough that an organization can install some modules without buying the entire package. Many organizations, for example, will install only an ERP finance or HR module and leave the rest of the functions for another day. [5]

\section{Improving a Company's Business Performance with ERP}

ERP's best hope for demonstrating value is as a sort of "battering ram" for improving the way an organization takes a customer order and processes that into an invoice and revenue-otherwise known as the order fulfillment process. That is why ERP is often referred to as back-office software. It doesn't handle the up-front selling process (although most ERP vendors have recently developed CRM-customer relationship management--software to do this). ERP focuses on how to provide greater company response and customer satisfaction. When a customer service representative enters a customer order into an ERP system, they have all the information necessary to complete the order (the customer's credit rating from the finance module, order history from the CRM module, the company's inventory levels from the warehouse module and the shipping dock's trucking schedule from the logistics module).

Employees in these different departments all see the same information and can update it. When one department finishes with the order, it is automatically routed via the ERP system to the next department. To find out where the order is at any point, employees need only to log into the ERP system to track it down. With luck, the order process moves like "a bolt of lightning through the organization, and customers get their orders faster and with fewer errors than before. ERP can apply that same magic to the other major business processes, such as sales forecasting, employee benefits or financial reporting. That, at least, is the dream of ERP. The reality is not so rosy.

The process of using inboxes may not have been efficient, but it was simple. Sales did its job, the warehouse did its job, and if anything went wrong outside of the department's walls, it was somebody else's problem. Not anymore. With ERP, the customer service representatives are no longer just typists entering someone's name into a computer and hitting the return key. The ERP screen makes them businesspeople. How important is this customer to us? It flickers with the customer's sales history and credit rating from marketing and finance and the product inventory levels from the warehouse. Did the customer pay for the last order yet? Will we be able to ship the new order on time? These are decisions that customer service representatives have never had to make before, and the answers affect the customer and every other department in the company. But it is not just the customer service representatives who have to wake up. People in the warehouse who used to keep inventory in their heads or on scraps of paper now need to put the information online. If they don't, customer service reps' screens will show low inventory levels and reps and segment managers will tell customers that the requested item is not in stock. Accountability, responsibility and communication have never been tested like this before.

People don't like to change, and ERP asks them to change how they do their jobs. That is why the value of ERP is so hard to pin down. The software is less important than the changes companies make in the ways they do business. If ERP is used to streamline order fulfillment and manufacturing and matches the company's resources to the customer's lifetime value to the firm, the organization should see the value from the software. If the organization simply installs the software without trying to improve the ways employees do their jobs, they may not see any value to the ERP implementation. [2] The new software could slow down the operations by simply replacing the old software that employees knew with new software that requires a great deal of learning to effectively implement.

\section{Why ERP Projects Often Fail}

At its simplest level, ERP is a set of best practices for performing the various duties in the departments of the organization, including finance, marketing, manufacturing and the warehouse. To get the most 
from the software, employees must adopt the work methods outlined in the software. If the employees in the different departments that use ERP do not agree that the work methods embedded into the software are better than the ones they currently use, they will resist using the software and will want IT to change the software to match the way they currently do things. This is where ERP projects often break down.

Political fights erupt over how-or even whetherthe software will be installed. IT gets bogged down in long, expensive customization efforts to modify the ERP software to fit with powerful business barons' wishes. Customizations make the software more unstable and harder to maintain when it finally does come to life. Because ERP covers so much of what a business does, a failure in the software can bring an organization to a halt-literally.

IT can fix the bugs pretty quickly in most cases and few big companies can avoid customizing ERP in some fashion. Every business is different and is bound to have unique work methods that a vendor cannot account for when developing its software. The mistake companies make is assuming that changing people's habits will be easier than customizing the software. [2] Getting employees to use the software to improve the way they do their jobs is by far the greater challenge. If the employees are resistant to change, then the ERP project is more likely to fail. Michael Donovan has conducted research on the topic of ERP and believes that there are five reasons for poor performance in ERP implementation:

1. Operating strategy did not drive business design and deployment

2. The implementation took much longer than expected

3. Pre-implementation preparation activities were done poorly, if at all

4. People were not well-prepared to accept and operate with the new system

5. The cost to implement was much greater than anticipated [2]

\section{Advantages of ERP}

For a large organization to be able to harmonize its complex operations allows it to focus its efforts on resources with the most profit potential. ERP systems can provide dependable data that can be used throughout the company. This is especially true in coordinating the marketing, sales and customer relationship functions. Before ERP, it was nearly impossible to implement complex, responsive marketing, sales, or logistics activities. Information sharing through ERP can result in exchanging information for inventory thus reducing costs and transferring information for time, helping the company to be more open to customer requests. Data sharing with vendors, including actual and forecasted sales, as well as future plans and forecasts, streamlines the supply chain and implements collaborative replenishment approaches.

Human resources functions can be improved through ERP by removing redundancy and tediousness of daily activities. This allows more time to be spent on value-added duties, which in turn leads to a more fulfilling job for employers. As employees become more empowered, they become more involved in decision making. With the right training and guidance, they can make decisions on their own without the close, watchful eye of their supervisor, allowing their supervisor to spend more time on value-added activities.

The use of integrated systems is becoming widespread in many industries, including the consumer products industry. The benefits are enhancing employee satisfaction, building customer loyalty and extending competitive advantage. "Coca Cola bolstered its success by providing a real time decision tool to its sales force while in the field. It placed marketing, promotional, and ad information at the fingertips of its sales force to ensure that retailers have the right product at the right time." [1] ERP attempts to help less compatible departments, such as accounting, production, and logistics, and streamlines their ability to share data. Barriers are broken down by ERP between departments, allowing fluid movement of critical data between functions. This movement allows organizations to reap many benefits. "Fujitsu, General Motors, and Boeing, to name a few, have experienced reduced cycle times for closing financials, streamlined global financial reporting, and internal resolutions to supply chain issues.” [1]

\section{Disadvantages of ERP}

As with any project, there are disadvantages that accompany the advantages. With ERP implementation, it is no different. Most disadvantages, however, relate directly to the implementation and the organization itself. According to an article by Traci Barker and Dr. Mark Frolick, Hershey and Whirlpool were two major 
corporations that had problems with ERP implementations. In 1999, Hershey had problems distributing its products globally because its new system targeted to handle filling and shopping orders was not functioning properly. Whirlpool experienced setbacks as well when their system was implemented to improve shipping and invoicing processing within the company. Both Hershey and Whirlpool's problems probably could have been avoided if certain aspects of the implementation were handled differently and according to the consultant's recommendations. "Although each individual ERP package may have its downfalls or customization problems, the bulk of ERP problems stem from an implementation that is not handled properly.” [1]

Considering that almost half of ERP implementations end in failure, proper planning, making employee involvement mandatory, and communicating with upper management should be at the top of the list when considering an ERP implementation.

\section{Critical Success Factors}

"Implementing the ERP system is itself a process that begins with planning for the system. After planning is complete, a project team embarks on and then moves through a number of discrete project phases. After the system is up and running, there may be a post-implementation review and later a stabilization phase.” [6]

\section{Appropriate Business and IT Legacy Systems}

Not every organization can have the same success with certain strategies of ERP implementation. "Business and IT legacy systems determine the degree of IT and organizational change required for ERP implementation success. The greater the complexity of legacy systems, the greater the amount of technological and organization change required.” [3]

\section{Business Plan and Vision}

ERP implementation does not happen overnight. It is a long process that requires patience, therefore, clear goals, a business plan and vision are needed to guide ongoing organization effort. [3]

\section{BPR (Business Process Reengineering)}

As with any type of implementation process, changes should occur during that process if any time it is determined that there is a more cost effective or efficient solution. "Enterprises should be willing to accept the embedded best practice, whenever possible, and model their business processes according to those depicted by the system.” [3]

\section{Change Management Culture and Program}

"Top management's recognition of the need for change is as important as the stronger the need for change, the more likely top management and stakeholders will support the ERP implementation.” [3] training and education are usually the first thing cut when the budget becomes a problem. But training and education are critical to the success of ERP implementation. [3]

\section{Communication}

Communication is the key to success of any new strategy or implementation. Expectations and goals help an organization recognize milestones in the ERP process. "Users need to know that the feedback they offer regarding the processes and problems with ERP will be received and acted on. Complete and open communication can leverage successes and facilitate enterprise-wide learning.” [3]

\section{ERP Teamwork and Composition}

Teamwork and composition are the keys to success for almost all projects started by a business. It is no different with an Enterprise Resource Planning project. An ERP project should involve all functional areas of the business and should command 100\% effort and cooperation between technical and business experts, as well as end users. [3] "It should be balanced, cross-functional, and comprise a mix of external consultants and internal staff so the internal staff can develop the necessary technical skills for design and implementation.” [3]

\section{Monitoring and Evaluation of Performance}

As with any project, it is necessary to have goals and milestones set in order to measure the effect of the implementation. These goals and milestones need to be actively monitored to track the progress of the implementation. [3]

\section{Project Champion}

A project champion is someone who communicates the ERP implementation plans and monitors and overall process. "ERP implementation usually requires employees putting in long hours in excess of their regular job duties. Long hours and stress may 
decrease employees' morale, requiring the project champion to boost the morale of project team members and ensure the commitment of all members.” [3]

\section{Project Management}

An essential part of success in ERP implementation is good project management. The implementation is commonly evaluated based on the degree to which time and budget requirements are met. "An individual or group of people should be given responsibility to drive success.” [3]

\section{Software Development, Testing and Troubleshooting}

Development and testing of ERP implementation systems must be well thought out and managed accordingly. "Organizations implementing ERP should work closely with vendors and consultants to resolve software problems. Rigorous and sophisticated software testing eases implementation. Integration of homegrown systems and specialized software products with the ERP suite is necessary to achieve the full benefits of the implementation.” [3]

\section{Top Management Support}

Identified as one of the most key success factors of ERP implementation, top management support is needed to publicly and explicitly support the implementation project and deem it top priority. "Senior management must be committed with their own involvement and willingness to allocate valuable resources to the implementation effort. This involves providing not only an appropriate amount of time and resources to get the job done, but also the necessary personnel for the implementation.” [3]

\section{CONCLUSION}

ERP allows an organization to maximize the seamless sharing of data throughout the organization, reduce costs, improve customer satisfaction and take advantage of e-business. There are many reasons for successful ERP implementation as there are for failed projects. However, success seems to often be measured by whether or not the project came in on time and under budget. Knowing what defines the ERP process and knowing what can make the implementation a success and what can make it a failure is critical.

\section{REFERENCES}

1. Barker, Traci and Mark Frolick. ERP Implementation Failure: A Case Study. Information Systems Management, 20(4), 43-49.

2. Donovan, Michael (2006). Successful ERP Implemenetation the First Time. [Online]. http://www.crm2day.com/erp/erp-2.php

3. Fui-Hoon Nah, Fiona, Zuckweller, Kathryn and Janet Jee-Shang Lau. (2003) ERP Implementation: Chief Information Officers' Perception of Critical Success Factors, International Journal of Human-Computer Interactions, 16(1), 5-22.

4. Koch, Christopher (2006) The ABC's of ERP. (Online)

http://www.cio.com/research/erp/edit/erpbasics .html.

5. M2PressWIRE (2006). It is predicted that the ERP market will grow by approximately 4\% through 2008.2 (Online). http://www.researchandmarkets.com/reports/c33 381.

6. Shanks, Graeme (2000). A Model of ERP Project Implementation. Journal of Technology. 